\title{
HDR and LDR Brachytherapy in the Treatment of Lip Cancer: the Experience of the Catalan Institute of Oncology
}

\author{
Arrate Querejeta Ayerra, MD', Estefania Palacios Mena, MD², Joan Pera Fabregas, MD, PhD³, \\ Cristina Gutiérrez Miguelez, MD, PhD³, Ferran Guedea, MD, PhD ${ }^{3}$ \\ 'Department of Radiation Oncology, Hospital Donostia, San Sebastián, Spain, 2Department of Radiation Oncology, Hospital de León, León, Spain, \\ ${ }^{3}$ Department of Radiation Oncology, Catalan Institute of Oncology, L'Hospitalet de Llobregat, Barcelona, Spain
}

\begin{abstract}
Purpose: Lip cancer can be treated by surgery, external radiotherapy, and/or brachytherapy (BT). In recent years, BT has become increasingly favored for this type of cancer. The aim of the present study was to analyze local control and survival of patients treated at our institution between July 1989 and June 2008.

Material and methods: We performed a retrospective study of 121 patients (109 males and 12 females) who underwent lip cancer brachytherapy from July 1989 to June 2008. Median age was 67 years and median follow-up was 31.8 months (range 20-188 months). Out of 121 patients, 100 (82.6\%) were treated with low dose rate (LDR) BT while the remaining 21 patients $(17.4 \%)$ received high dose rate (HDR) BT.

Results: The most common cell type was squamous cell carcinoma (115 cases; $95 \%)$ and most tumors were located on the lower lip (107 patients; 88.4\%). Most cases were either stage T1 (62 patients; $51.2 \%$ ), or T2 (44 cases; $36.4 \%$ ). After 15 years of follow-up, overall survival was $89.5 \%$, cause-specific survival $97.8 \%$, and disease-free survival $86.6 \%$. Local, regional, and distant control at 15 years were $90 \%, 92 \%$, and $98.8 \%$, respectively. Grade 3 mucosal toxicity was observed in $23 \%$ of patients treated with LDR compared to $33 \%$ of HDR patients, and grade 4 mucosal toxicity in $9 \%$ versus $0 \%$ in the HDR group.

Conclusions: Our findings confirm that brachytherapy is an effective treatment for lip cancer. The results from our series are in line with those published elsewhere. Based on our limited data, HDR appears to be equally as good as LDR, although this needs to be confirmed by further studies.
\end{abstract}

Key words: lip cancer, brachytherapy, radiotherapy dosage.

\section{Purpose}

In the United States, lip cancer is among the most common type of head and neck skin cancers, with the annual incidence estimation of 1.8 cases per 100000 inhabitants. Numerous etiological factors such as: alcohol intake, inadequate oral hygiene, tobacco use, sun exposure, and precancerous lesions, have been related to lip cancer, although tobacco use (especially pipes) and sun exposure have the strongest association with this disease. Most patients are men, with a median age of 65 [1]. In $95 \%$ of cases, the tumor is located on the lower lip. More than $90 \%$ of lip cancers are squamous cell carcinomas while approximately $10 \%$ are basal cell carcinomas. Other histological types are exceptional [2].

Lip cancer is a slow-growing, localized cancer often diagnosed at an early stage; as a result, survival rates are usually quite high. At diagnosis, only $5-10 \%$ of patients have nodal involvement, usually in cases with undifferentiated cells and advanced stages [3,4]. Distant metastases are infrequent and associated with very large tumors that are not locally controlled. Prognosis depends on the size of primary lesion, nodal involvement, perineural and lymphovascular invasion, and age, with a worse prognosis in younger patients [5]. Five year survival is $90-95 \%$ for $\mathrm{T} 1$ tumors, and $75-85 \%$ for T2, with a drastic drop off in survival for patients at stage T3-T4 [6].

Treatment typically includes radiotherapy (brachytherapy in general) and/or surgery. For a long time, low dose rate (LDR) brachytherapy was the treatment of choice, although high dose rate (HDR) BT was recently introduced. Brachytherapy as a treatment modality is recommended in up to $90 \%$ of lip tumor cases, with excellent results in local control, survival, and cosmetic outcome [7-17] (Table 1). The 
Table 1. PSA level before and after salvage HDR-BT

\begin{tabular}{|c|c|c|c|c|c|c|c|c|}
\hline \multirow[t]{2}{*}{ Author } & \multirow[t]{2}{*}{ \# Cases (stage) } & \multirow[t]{2}{*}{ BT Dose } & \multicolumn{6}{|c|}{5 year (10 year*) local failure rates } \\
\hline & & & All & $\mathrm{T} 1$ & $\mathrm{~T} 2$ & T3 & T4 & PSR \\
\hline $\begin{array}{l}\text { Gerbaulet et al., } \\
1978 \text { [10] }\end{array}$ & $316(\mathrm{~T} 1-\mathrm{T} 4)$ & $\begin{array}{l}\mathrm{Ra}^{206} \\
\mathrm{Ir} \mathrm{r}^{192}\end{array}$ & $4.2 \%$ & $0 \%$ & $2.1 \%$ & $7.7 \%$ & $4 / 6$ & \\
\hline $\begin{array}{l}\text { Pigneux et al., } \\
1979 \text { [23] }\end{array}$ & 93 & $\begin{array}{c}1 r^{192} \\
65-75 \text { Gy }\end{array}$ & $4.5 \%$ & $2.2 \%$ & $4.3 \%$ & $5.2 \%$ & - & \\
\hline $\begin{array}{l}\text { Mazeron et al., } \\
1983 \text { [21] }\end{array}$ & 1896 (T1-T4) & $\begin{array}{l}629 \mathrm{Ra}^{206} \\
\mathrm{Cs}^{137} \\
1267 \mathrm{Ir}^{192}\end{array}$ & $\begin{array}{c}10.9 \% \\
3.4 \%\end{array}$ & $\begin{array}{l}8.3 \% \\
1.6 \%\end{array}$ & $\begin{array}{l}10.8 \% \\
3.4 \%\end{array}$ & $\begin{array}{l}7 / 12 \\
10 \%\end{array}$ & $1 / 15$ & \\
\hline $\begin{array}{l}\text { Cowen et al., } \\
1990 \text { [8] }\end{array}$ & 248 & $\begin{array}{c}1 r^{192} \\
60-81 G y\end{array}$ & $4 \%$ & $3.4 \%$ & $5.4 \%$ & $3.7 \%$ & $6 / 9$ & \\
\hline $\begin{array}{l}\text { Orrechia et al., } \\
1991 \text { [22] }\end{array}$ & $47(\mathrm{~T} 1-\mathrm{T} 2)$ & $\begin{array}{c}1 r^{192} \\
60-80 \mathrm{~Gy}\end{array}$ & $6.4 \%$ & $6.4 \%$ & - & - & & \\
\hline $\begin{array}{l}\text { Van Limbergen } \\
\text { et al., 1993 [16] }\end{array}$ & $\begin{array}{c}2794 \text { (T1-T4) } \\
\text { PSR }\end{array}$ & $\begin{array}{c}1 r^{192} \\
40-90 \mathrm{~Gy} \\
\mathrm{Cs}^{137}\end{array}$ & $\begin{array}{c}6 \% \\
10 \% *\end{array}$ & $\begin{array}{c}5 \% \\
7.5 \%\end{array}$ & $\begin{array}{l}8.2 \% \\
12 \%\end{array}$ & $\begin{array}{l}19 \% \\
30 \%\end{array}$ & $0 / 24$ & $\begin{array}{l}17 \% \\
23 \%\end{array}$ \\
\hline $\begin{array}{l}\text { Cerezo et al., } \\
1993 \text { [19] }\end{array}$ & 117 & XRT ( \pm surgery) & $4 \%$ & $4 \%$ & $6 \%$ & - & & \\
\hline $\begin{array}{l}\text { Gerbaulet et al., } \\
1994 \text { [11] }\end{array}$ & 231 & $\begin{array}{c}1 r^{192} \\
70-85 \text { Gy }\end{array}$ & $5.6 \%$ & na & na & na & na & \\
\hline $\begin{array}{l}\text { Beauvois et al., } \\
1994 \text { [7] }\end{array}$ & 237 (T1-T4) & $\begin{array}{c}\mid r^{192} \\
65-68 \mathrm{~Gy}\end{array}$ & $\begin{array}{l}5 \% \\
8 \% *\end{array}$ & & & & - & \\
\hline $\begin{array}{l}\text { Farrus et al., } \\
1996 \text { [9] }\end{array}$ & $72(\mathrm{~T} 1-\mathrm{T} 3) \mathrm{PSR}$ & $\begin{array}{c}1 r^{192} \\
62-67 \text { Gy }\end{array}$ & $11 \%$ & $10 \%$ & $7 \%$ & $25 \%$ & - & $13 \%$ \\
\hline $\begin{array}{l}\text { Visscher et al., } \\
1996 \text { [17] }\end{array}$ & 108 (T1-T3) & $\begin{array}{l}\text { Ir } 192 \text { 48-70 Gy } \\
\text { XRT, Electrons, } \\
\text { photons }\end{array}$ & $4.6 \%$ & $1.1 \%$ & $23.5 \%$ & $0 / 2$ & & \\
\hline $\begin{array}{l}\text { Tombolini et al., } \\
1998[14]\end{array}$ & 57 (T1-T3) & $\begin{array}{l}1 r^{192} \\
62 \mathrm{~Gy}\end{array}$ & $10 \%$ & na & na & na & - & \\
\hline
\end{tabular}

$X R T$ - indicates external beam radiation therapy, na - not available, BT - brachytherapy, PSR - post surgical recurrences

main purpose of this retrospective study was to analyze our results in terms of local control and survival in brachytherapy patients treated at our institution between July 1989 and June 2008 .

\section{Material and methods}

From July 1989 to June 2008, a total of 121 patients diagnosed with lip cancer were treated with brachytherapy, with a median follow up of 31.8 months (range 20-188 months). Tumor staging was determined by clinical history, physical examination, histological diagnosis, and metastatic extension of the disease. The patient and tumor characteristics and treatment of 121 patients are described in Table 2. Out of 121 patients in our series, 109 were males $(90.1 \%)$ and 12 females (9.9\%). The median age at the beginning of treatment was 67 years. The most common tumor type was squamous cell carcinoma (115 cases; 95\%), followed by basal cell carcinoma ( 3 cases; $2.5 \%$ ), and cystic adenoid carcinoma ( 1 case; $0.8 \%$ ). In 2 cases $(1.7 \%$ ) histological results were not available. Most tumors were located on the lower lip (107 patients; $88.4 \%$ ), followed by the upper lip ( 8 cases; $6.6 \%$ ), and commissure of lip (4 cases; $3.3 \%$ ). Tumor staging was performed according to the TNM classification system, with 5 patients $(4.1 \%)$ at stage
Tis, 62 cases $(51.2 \%)$ at stage $\mathrm{T} 1,44(36.4 \%)$ stage $\mathrm{T} 2$, 3 cases $(2.5 \%)$ stage $\mathrm{T} 4$, and in 7 patients $(5.8 \%)$ the stage was unknown.

BT with guide needles was performed in most cases (109 patients; $90.1 \%$ ) while the remaining 12 patients $(9.9 \%)$ were treated with plastic tubes. A total of 21 patients $(17.4 \%)$ received high dose rate (HDR) brachytherapy while 100 patients $(82.6 \%)$ underwent low dose rate (LDR) procedures with Iridium-192 (I-192) as radionuclide. Dosimetry was adapted from the Paris System with some modifications depending on the location. The dose varied between 45 Gy and 50 Gy for HDR treatments and between $60 \mathrm{~Gy}$ and $70 \mathrm{~Gy}$ for LDR.

\section{Results}

Survival analysis was performed for the whole series. Differential analysis between LDR and HDR was not possible due to the limited number of patients treated by HDR. At 15 years, overall survival was $89.5 \%$, cause-specific survival $97.8 \%$ and disease-free survival $86.6 \%$ (Figs. 1-3). Local, regional, and distant control, were $90 \%, 92 \%$, and 98.8\%, respectively (Figs. 4-6).

Toxicity was scored according to the Radiation Therapy Oncology Group/European Organization for Research 
and Treatment of Cancer (RTOG/EORTC) scales. Grade 3 mucosal toxicity was observed in $23 \%$ of patients treated with LDR compared to $33 \%$ of the HDR group, and grade 4 mucosal toxicity in $9 \%$ of LDR cases versus $0 \%$ of HDR patients. HDR and LDR BT showed similar results in terms of chronic fibrosis, telangiectasias, chronic alopecia and atrophy, although HDR was slightly superior to LDR. None of these differences, however, were significant as only a small percentage of cases experience any of these alterations (Grade 1 or 2 in all cases).

\section{Discussion}

Lip cancer is a common malignancy of the head and neck region and is frequently diagnosed at an early stage. A number of modalities, including surgery, external radiotherapy, and brachytherapy are all very successful in treatment of these lesions. However, because numerous different treatments have shown to provide good results, considerable uncertainty exists with regards to the treatment of choice.

At present, brachytherapy is one of the most important therapeutic treatments for lip cancer, because it can be used as a monotherapy, after surgery, or as a localized boost after external beam radiation therapy. Experience has shown that a high tumor dose is required to achieve local control [18]. The main treatment aim is to achieve tumor control while limiting toxicity and preserving function to the maximum extent possible. In stage T2-T3 cancers, surgery does not always completely eliminate the tumor, even with a surgical margin of safety, as evidenced by the incidence of local recurrences described in various studies [19-23] (Table 1). Brachytherapy offers numerous advantages, including high localized dose with rapid fall-off, and short overall treatment duration. The primary tumor volume receives a total dose that cannot be delivered by external beam radiotherapy alone, and rapid falloff allows sparing of critical normal tissues.

For lip cancer, especially in early stages, results show that brachytherapy is similar to surgery in terms of local control and survival. Considerable experience has been accumulated with LDR brachytherapy. Gerbaulet et al. [11] presented long-term results of 231 patients treated with LDR I-192 brachytherapy, reporting a $94.4 \%$ local control

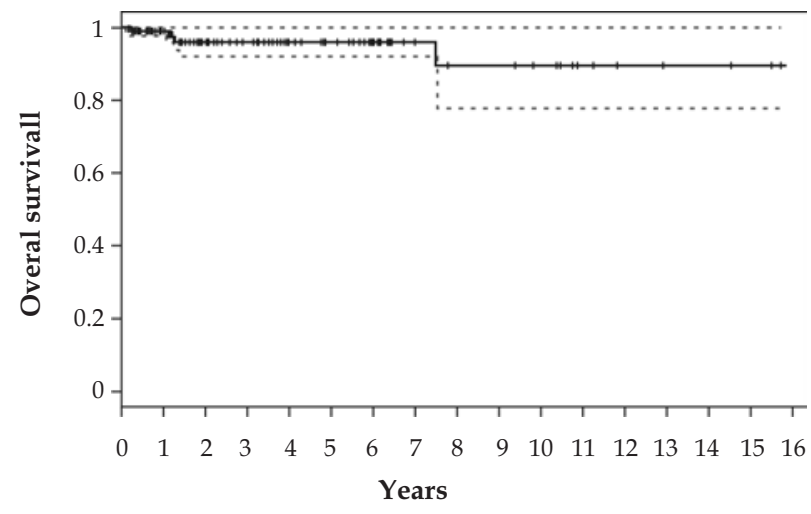

Fig. 1. Kaplan-Meier estimation of overall survival
Table 2. Clinical characteristics of patients

\begin{tabular}{lc}
\hline Patient and treatment characteristics & (\%) \\
\hline Age (median) & 67 years \\
\hline Sex & \\
Males & $90.1 \%$ \\
Females & $9.9 \%$ \\
\hline Tumour size & \\
Tis & $4.1 \%$ \\
T1 & $51.2 \%$ \\
T2 & $36.4 \%$ \\
T3 & $0 \%$ \\
T4 & $2.5 \%$ \\
Lack of & $5.8 \%$ \\
\hline Tumour localization & \\
Commissure & $3.3 \%$ \\
Lower lip & $88.4 \%$ \\
Upper lip & $6.6 \%$ \\
Lack of & $1.7 \%$ \\
\hline Histology & \\
Squamous cell carcinoma & $95 \%$ \\
Basal cell carcinoma & $2.5 \%$ \\
Cystic adenoid & $0.8 \%$ \\
Lack of & $1.7 \%$ \\
\hline Applicators & \\
Guide needles & $92.1 \%$ \\
Plastic tubes & \\
\hline Dose rate & \\
HDR (45-50 Gy) & \\
LDR (60-70 Gy) & \\
\hline & \\
\hline
\end{tabular}

rate. Beauvois et al. [7] reviewed 237 patients treated with LDR and found a 95\% local control rate at 5 years. Urraca et al. [15] performed a retrospective analysis of overall survival in 66 patients treated with LDR brachytherapy, reporting 2- and 5-year survival rates of $93 \%$ and $73 \%$, respectively.

The use of HDR brachytherapy is becoming more popular in the treatment of lip cancer. It offers the advantage of optimizing dose distribution by varying dwell times. Guinot et al. [12] retrospectively evaluated 39 patients treated with HDR (40.5-45 Gy), with a mean follow-up of 18 months. These authors reported an overall survival of $91 \%$ and local control rates of $100 \%$ for stage T1 tumors,

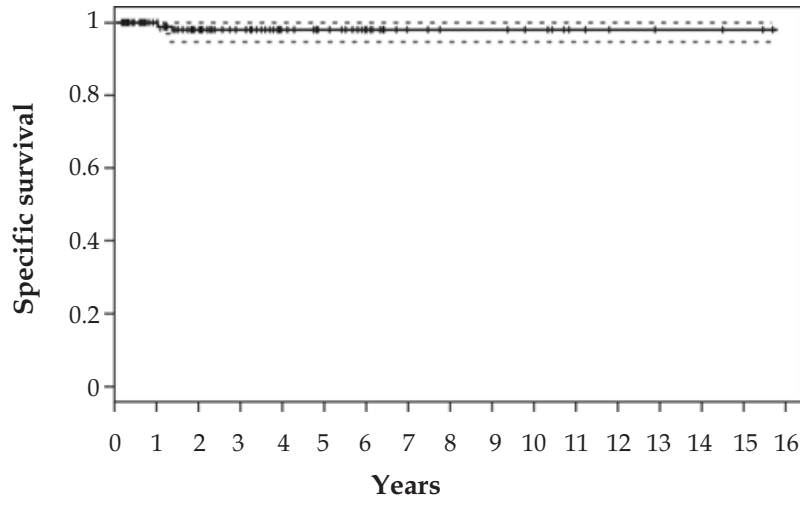

Fig. 2. Kaplan-Meier estimation of disease-specific survival 


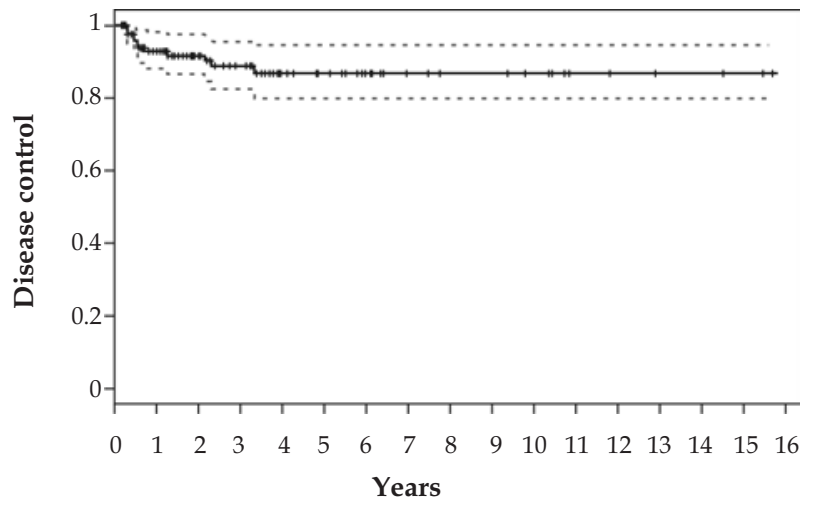

Fig. 3. Kaplan-Meier estimation of disease control

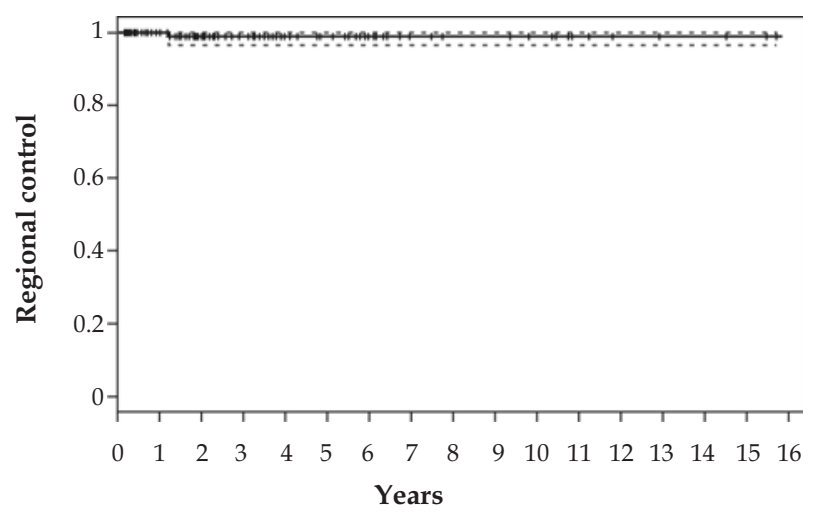

Fig. 5. Kaplan-Meier estimation of regional control

$83 \%$ in stage $\mathrm{T} 2$, and $75 \%$ in stage $\mathrm{T} 4$. The authors concluded that HDR is at least as effective and safe as LDR brachytherapy in treating small and intermediate lip carcinomas.

However, aside from the above-mentioned studies, relatively few investigations have been published concerning HDR lip cancer treatment. Those available include limited number of patients and lack long-term follow-up. In our study, only 21 patients $(17.4 \%)$ received HDR brachytherapy, making it impossible to perform a differential analysis between LDR and HDR. The lack of large, long-term studies makes it difficult to define the effectiveness of HDR in terms of local control, survival, and cosmetic and functional results. Likewise, it is not yet possible to establish the optimal total dose, number of fractions, and dose per fraction.

\section{Conclusions}

In conclusion, the results of the present study confirm brachytherapy as an effective treatment for lip cancer with results comparable to other treatment modalities. The results from our centre are in line with those published elsewhere. Moreover, HDR appears to be as good as LDR in treating lip carcinomas, however this can only be confirmed by more comprehensive long-term study.

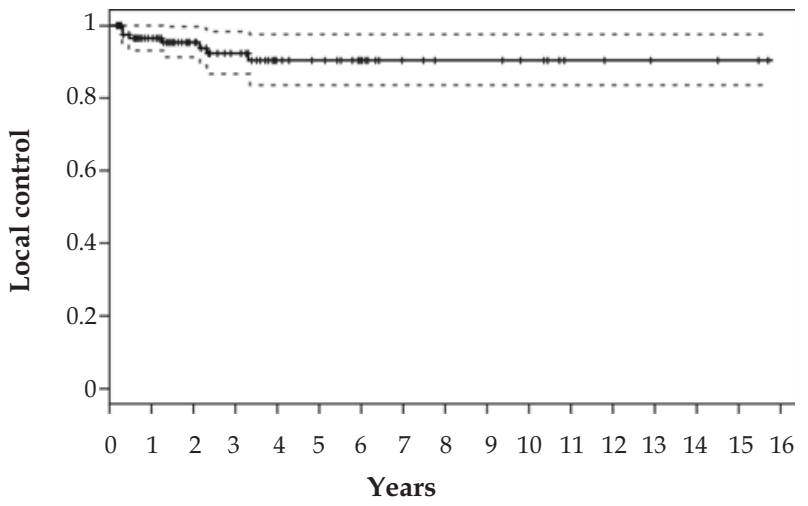

Fig. 4. Kaplan-Meier estimation of local control

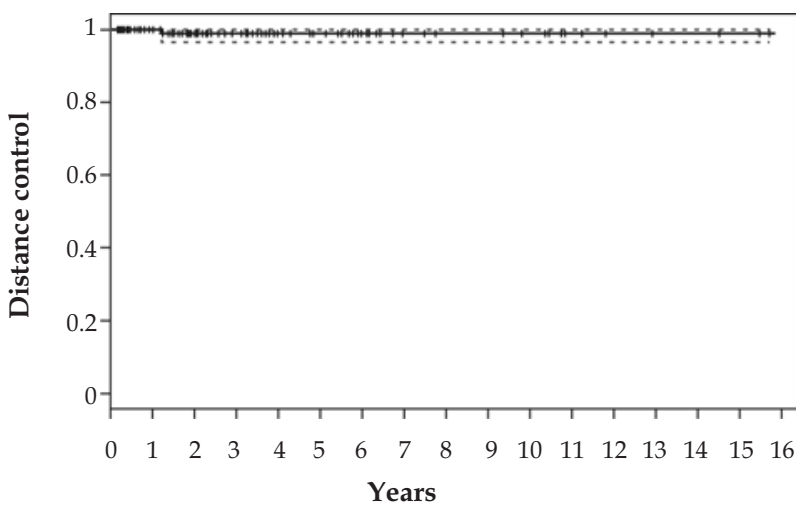

Fig. 6. Kaplan-Meier estimation of distant control

\section{References}

1. Menck HR, Garfinkel L, Dodd GD. Preliminary report of the National Cancer Data Base. CA Ca J Clin 1991; 41: 7-18.

2. Gerbaulet A, Vanlimbergen E. Lip cancer. In: The GEC-ESTRO handbook of brachytherapy. Gerbaulet A, Pötter R, Mazeron JJ, Meertens H, VanLimbergen E (eds.). ACCO Ed, Leuven 2002; 227-236.

3. Stimson P, Schantz Louis B et al. Lip cancer. In: Cancer Principles \& Practice of Oncology. Lippincot Williams \& Wilkins Inc. Philadelphia-New York 1997; 773-775.

4. Wang CC. Cancer of the oral cavity. In: Radiation therapy for head and neck neoplasms. Wiley-Liss Ed, Toronto 1997; 107-185.

5. Boddie Jr AW, Fischer EP, Byers RM. Squamous Carcinoma of the Lower Lip in Patients Under 40 Years of Age. South Med J 1977; 70: 711.

6. Million RR, Cassisi NJ, Mancuso AA. Oral cavity. In: Million RR, Cassisi NJ (ed.). Management of head and neck cancer. J.B. Lippincot Company, Philadelphia 1994; 329-359.

7. Beauvois S, Hoffstetter S, Peiffert D et al. Brachytherapy for lower lip epidermoid cancer: tumor and treatment factors influencing recurrences and complications. Radioth Oncol 1994; 33: 195-203.

8. Cowen D, Thomas L, Richaud P et al. Cancer des lèvres. Résultas du traitement de 299 patients. Ann Oto-Laryngol 1990; 107: 121-126.

9. Farrús B, Pons F, Sánchez-Reyes A et al. Quality assurance of interstitial brachytherapy technique in lip cancer: comparison 
of actual performance with the Paris System recommendations. Radiother Oncol 1996; 38: 145-151.

10. Gerbaulet A, Chassagne D, Hayem M et al. L'épithélioma de la lèvre. Une série de 335 cas. J Radiol Electrol 1978; 59: 603-610.

11. Gerbaulet A, Grande C, Chirat E. Braquiterapia intersticial con Iridio en el carcinoma de labio: análisis de 231 casos tratados en el Institut Gustave Roussy. Oncología 1994; 17: 45-49.

12. Guinot JL, Arribas L, Chust ML et al. Lip cancer treatment with high dose rate therapy. Radioth Oncol 2003; 69: 113-115.

13. Nguyen TD, Douchez J, Combes J et al. Recidives tumorales pures de cancers labiaux. Traitement de ratrappage par curiethérapie interstitielle. Ann Radiol 1982; 23: 207-209.

14. Tombolini V, Bonanni A, Valeriani M et al. Brachytherapy for squamous cell carcinoma of the lip. The experience of the Institute of Radiology of the University of Rome "La Sapienza". Tumori 1998; 84: 478-482.

15. Urraca JM, Pera J, Guedea F et al. Braquiterapia en neoplasias de labio. La experiencia del Instituto Catalán de Oncología (ICO). Oncología 2001; 3: 310-313.

16. Van Limbergen E, Ding W, Haustermans K et al. Lip cancer: local control results of low dose rate brachytherapy. The GEC-ESTRO 1993 survey on 2800 cases. [unpublished data presented at the annual GEC ESTRO meeting Venice 1993].

17. Visscher JGAM, Grond AJK, Blotke G et al. Results of radiotherapy for squamous cell carcinoma of the vermilion border of the lower lip. A retrospective analysis of 108 patients. Oncol 1996; 39: 9-14.

18. Mazeron JJ, Ardiet JM, Haie-Méder C et al. GEC-ESTRO recommendations for brachytherapy for head and neck squamous cell carcinomas. Radioth Oncol 2009; 91: 150-156.

19. Cerezo L, Liu FF, Tsang R et al. Squamous cell carcinoma of the lip: analysis of the Princess Margaret Hospital experience. Radiother Oncol 1993; 28: 142-147.

20. Mazeron JJ, Richaud P. Results of ionizing radiation treatment of 2274 epidermoid epitheliomas of the lips. Rev Stomatol Chir Maxillofac 1983; 84: 305-306.

21. Mazeron JJ, Richaud P. Treatment of epidermoid epithelioma of the lip. 2363 cases. Presse Med 1983; 12: 2183.

22. Orecchia R, Rampino $M$, Gribaudo $S$ et al. Interstitial brachytherapy for carcinomas of the lower lip. Results of treatment. Tumori 1991; 77: 336-338.

23. Pigneux J, Richaud PM, Lagarde C. The place of interstitial therapy using 192 iridium in the management of carcinoma of the lip. Cancer 1979; 43: 1073-1077. 